\title{
SOURCES OF VARIATION IN \\ Holding Returns For Fed \\ Funds Futures Contracts
}

\section{JAMES D. HAMILTON* \\ TATSUYOSHI OKIMOTO}

This study relates predictable gains from positions in fed funds futures contracts to violations of the expectations hypothesis of the term structure of interest rates. Although evidence for predictable gains from positions in short-horizon contracts is mixed, we find that gains in longer horizon contracts can be well described using Markov-switching models, with predictability associated with particular episodes in which economic activity was weak and variability in the returns to these contracts was quite high. (C) 2010 Wiley Periodicals, Inc. Jrl Fut Mark $31: 205-229,2011$

\section{INTRODUCTION}

The strong formulation of the expectations hypothesis of the term structure of interest rates conjectures that the expected holding yields from long-term and short-term bonds should be the same, while the weak form of the expectations

\footnotetext{
We are grateful to Michael Bauer, Brent Bundick, Eric Swanson, and an anonymous referee for comments on an earlier draft. Okimoto thanks the JSPS Postdoctoral Fellowships for Research Abroad for financial support.

${ }^{*}$ Correspondence author, Department of Economics, 0508, University of California, San Diego, La Jolla, California. Tel: (858) 534-5986, Fax: (858) 534-7040, e-mail: jhamilton@ucsd.edu
}

Received August 2009; Accepted May 2010

- James D. Hamilton is a Professor at the Department of Economics, University of California, San Diego, California.

- Tatsuyoshi Okimoto is an Associate Professor at the Graduate School of International Corporate Strategy, Hitotsubashi University, Tokyo, Japan. 
hypothesis allows the holding yields to differ by a constant term premium. These are approximately equivalent ${ }^{1}$ to the claims that the long rate should equal the average of expected future short rates under the strong form, or an average plus a constant term premium under the weak form. Although these are a priori appealing hypotheses, even the weak forms have been consistently rejected by empirical researchers; see Campbell and Shiller (1991), Evans and Lewis (1994), Bekaert, Hodrick, and Marshall (1997), and Cochrane and Piazzesi (2005), among many others. Notwithstanding, Rudebusch (1995) and Longstaff (2000) suggested that the expectations hypothesis may not be a bad approximation at the shortest end of the term structure.

Another well-established empirical finding is that short-term interest rates can be usefully described using Markov regime-switching models such as proposed by Hamilton (1989); see for example Hamilton (1988), Garcia and Perron (1996), Gray (1996), Ang and Bekaert (2002), Sims and Zha (2006), and Inoue and Okimoto (2008). A number of researchers have reported considerable improvements in models of the term structure of interest rates by incorporating these regime changes, including Bansal and Zhou (2002), Evans (2003), Dai, Singleton, and Yang (2007), and Ang, Bekaert, and Wei (2008).

A separate literature has examined whether expected gains from long positions in fed funds futures contracts are zero, or equivalently, whether these contracts incorporate an optimal forecast of future fed funds rates. Previous studies include Krueger and Kuttner (1996), Rudebusch (1998), Kuttner (2001), Sack (2004), Gürkaynak, Sack, and Swanson (2007), Piazzesi and Swanson (2008), and Hamilton (2009). While all these studies support the view that fed funds futures provide an excellent forecast of fed funds rates, they have often also found some evidence of predictable gains, particularly for fed funds futures contracts at longer maturities.

The purpose of the present study is to investigate the extent to which changes in regime can account for these predictable gains from positions in fed funds futures contracts. A companion study by Bundick (2007) has also fit regime-switching models to fed funds futures. Bundick's analysis begins in 1995, whereas some of the most interesting features we highlight occurred in the early 1990s. Bundick studied the $n$-month gains from holding these contracts to maturity, whereas we use 1-month holding gains throughout, which simplifies the implied dynamic structure under both null and alternative hypotheses. And whereas Bundick's primary focus was on constructing an optimal forecast of the future fed funds rate, here our emphasis is on characterizing the nature of the implicit risk premium associated with these contracts.

${ }^{1}$ See Campbell, Lo, and MacKinlay (1997, Section 10.2). 
Like Piazzesi and Swanson (2008) and Hamilton (2009), we find the most persuasive evidence of predictable gains for the longer horizon futures contracts. Our results suggest that predictable gains are primarily associated with one particular regime that is characterized by unusual volatility in the holding gains and tends to coincide with episodes of weak economic growth or recession. These results also complement the findings by Cochrane and Piazzesi (2005) that predicted excess holding yields from long-term bonds are countercyclical, and by Piazzesi and Swanson (2008) that expected holding gains from long positions in fed funds futures contracts are countercyclical. We suggest that at least in the case of fed funds futures contracts, this phenomena is better characterized as a feature confined to particular historical episodes rather than present throughout the sample.

The plan of the study is as follows. In the following section we briefly explore the theoretical connection between the term structure of interest rates and predictable gains from fed funds futures contracts. Empirical results are presented in the later section, and implications for the most recent behavior of fed funds futures are noted in the penultimate section. The final section concludes.

\section{RISK PREMIA IN INTEREST RATES AND FED FUNDS FUTURES}

Let $P_{n t}$ denote the price paid at time $t$ for a pure-discount bond that will be worth $\$ 1$ with certainty at $t+n$ and let $M_{t}$ denote the stochastic discount factor. Standard finance theory (e.g., Campbell, Lo, \& MacKinlay, 1997, p. 428) asserts that

$$
P_{n t}=E_{t}\left[P_{n-1, t+1} M_{t+1}\right]
$$

implying

$$
P_{n t}=E_{t}\left[M_{t, t+n}\right]
$$

for $M_{t, t+n}=\prod_{i=1}^{n} M_{t+i}$ Consider a forward contract agreed to at date $t$ to buy a one-period bond at $t+n$, whose value will be $\$ 1$ at $t+n+1$. Let $S_{n t}$ denote the price agreed to under the contract and $P_{1, t+n}$ what the actual price of the bond turns out to be. Absence of arbitrage requires the forward price to satisfy

$$
E_{t}\left[M_{t, t+n}\left(P_{1, t+n}-S_{n t}\right)\right]=0
$$

or

$$
S_{n t}=\frac{E_{t}\left[M_{t, t+n} P_{1, t+n}\right]}{E_{t}\left[M_{t, t+n}\right]} .
$$


Evaluating (1) for a 1-period bond at date $t+n$,

$$
P_{1, t+n}=E_{t+n}\left[M_{t+n+1}\right] .
$$

Substituting (3) into (2) and using the Law of Iterated Expectations,

$$
S_{n t}=\frac{E_{t}\left[M_{t, t+n+1}\right]}{E_{t}\left[M_{t, t+n}\right]}=\frac{P_{n+1, t}}{P_{n t}} .
$$

This forward price $S_{n t}$ will be recognized as the reciprocal of the gross forward interest rate; see Campbell et al. (1997, Equation 10.1.7).

When the term structure of interest rates slopes up (bonds of higher maturities $n$ have higher yields), the value of $S_{n t}$ for a given $t$ would typically be a decreasing function of the horizon $n$. Thus in a stationary environment, a term premium that induces an average positive slope to the term structure would result in $S_{n, t-1}-S_{n-1, t}<0$ on average.

Fed funds futures contracts are settled based on the average value of the overnight fed funds rate during the expiry month. Insofar as these behave like forward contracts on the future price of one-period bonds, fed funds futures contracts should inherit the same pricing premia as the term structure of interest rates. Let $f_{n t}$ denote the interest rate implied as of the last day of month $t$ by a fed funds futures contract expiring $n$ months subsequently, and $r_{t+n}$ the actual average fed funds rate for month $t+n$. In the absence of arbitrage, the futures contracts must be priced such that

$$
E_{t}\left(M_{t, t+n} f_{n, t}\right)=E_{t}\left(M_{t, t+n} r_{t+n}\right) .
$$

Note that if the fed funds rate at time $t+n$ were given by one minus the risk-free one-period bond price at that date, that is, if

$$
r_{t+n}=1-P_{1, t+n}
$$

then the fed funds futures rate $f_{n t}$ would be exactly equal to $1-S_{n t}$ under the assumption of no arbitrage. In practice, however, we should not expect this condition to hold exactly. Fed funds contracts are based on a monthly average of daily values for overnight fed funds, which differs from the end-of-month concept $P_{1 t}$. Moreover, lending overnight fed funds is not completely risk free, the yield is the nonlinear function $\left(1 / P_{1 t}\right)-1$ rather than $1-P_{1 t}$, and margin requirements are marked to market daily unlike a pure forward contract. For these reasons, $f_{n t} \simeq 1-S_{n t}$ is only an approximation. Nonetheless, it would be surprising if fed funds futures contracts behave grossly out of line with risk premia in the term structure. 
Following Piazzesi and Swanson (2008), we define the one-month holding gain $u_{n t}$ to be the profit (or loss if negative value) from taking the long position in an $n$-month contract on the last day of month $t-1$ and closing the position on the last day of month $t$ :

$$
u_{n t}=f_{n, t-1}-f_{n-1, t} .
$$

For $n=1$, the value of $u_{1 t}$ is the difference between the 1-month futures rate at the end of month $t-1$ and the actual fed funds rate experienced in month $t$ :

$$
u_{1 t}=f_{1, t-1}-r_{t} .
$$

The strong form of the expectations hypothesis would require $E_{t-1}\left(u_{n t}\right)=0$, and the weak form $E_{t-1}\left(u_{n t}\right)=c_{n}$. A violation of the strong form of the expectations hypothesis in the form of a positively sloped yield curve would cause $S_{n, t-1}-$ $S_{n-1, t}<0$ on average, under which we would expect $u_{n t}$ to be positive on average. If the long rate is above the average of expected future short rates, then the forward rate should be above the expected future spot rate, and the interest rate $f_{n t}$ associated with a given contract should on average decline as the contract gets closer to expiry, i.e., as $n$ decreases and $t$ increases, implying a positive average value for $u_{n t}$. The positive average slope to the yield curve is of course well-documented, and Piazzesi and Swanson (2008) found evidence for positive values of $u_{n t}$ for all $n$. However, just as the evidence against the expectations hypothesis of the term structure is weakest for securities with maturity $n$ less than 2 months (Longstaff, 2000; Rudebusch, 1995), evidence for predictable variation in the fed funds futures revisions $u_{n t}$ is weakest for small $n$ (Hamilton, 2009; Piazzesi \& Swanson, 2008).

\section{EMPIRICAL RESULTS}

\section{Autoregressive Specifications}

The basic data used in this study are the monthly changes in the prices of contracts with one to six months of settlement and purchased from the Chicago Board of Trade. We calculate $f_{n t}$ (in basis points) from the end-of-month closing contract price $Q_{n t}$ as $f_{n t}=100 \times\left(100-Q_{n t}\right)$ and $u_{n t}$ from (6). The sample period is from November 1990 to June $2006 .^{2}$ The main purpose of the study is to examine possible regime switches in the one-month holding gains associated with long positions in contracts of various maturities.

${ }^{2}$ Federal funds futures price data are available from October 1988. However, we chose November 1990 as the beginning of our sample, since the longer horizon contracts were not traded frequently in the first two years of the data. Our sample ends before the most recent turbulence in fed funds and other financial markets. 
TABLE I

Estimation Results for the AR(1) Model

\begin{tabular}{lcccccc}
\hline$n$ & 1 & 2 & 3 & 4 & 5 & 6 \\
\hline$\alpha$ & 2.716 & 3.106 & 2.511 & 3.071 & 3.536 & 4.076 \\
Std. error & 0.744 & 1.000 & 1.015 & 1.284 & 1.466 & 1.667 \\
$\phi$ & -0.011 & 0.147 & 0.366 & 0.372 & 0.357 & 0.330 \\
Std. error & 0.076 & 0.074 & 0.074 & 0.069 & 0.071 & 0.071 \\
$\sigma$ & 9.70 & 13.05 & 14.50 & 16.77 & 19.24 & 21.91 \\
Std. error & 0.54 & 0.68 & 0.76 & 0.87 & 0.95 & 1.06 \\
$R^{2}$ & 0.000 & 0.024 & 0.139 & 0.143 & 0.129 & 0.110 \\
Log-likelihood & -686 & -742 & -761 & -788 & -814 & -838 \\
\hline
\end{tabular}

As a starting point, we estimated a simple Gaussian AR(1) model,

$$
u_{n t}=\alpha_{n}+\phi_{n} u_{n, t-1}+\sigma_{n} \varepsilon_{n t}, \varepsilon_{n t} \sim N(0,1)
$$

for horizons $n=1, \ldots, 6$ months using maximum likelihood estimation (MLE), in this case equivalent to ordinary least squares. The estimation results are summarized in Table I. As can be seen, the constant terms are estimated to be positive and statistically significant for all horizons, consistent with an upward-sloping yield curve or positive risk premia on longer term bonds. The $\mathrm{AR}(1)$ terms are significantly positive for all horizons longer than one month, suggesting variation over time in these risk premia. The implied average holding gain given by $\mu_{n}=\alpha_{n} /\left(1-\phi_{n}\right)$ is increasing in the horizon $n$, ranging from 2.7 to 6.1 basis points per month (32-73 bp per year), which is fairly consistent with the results of Piazzesi and Swanson (2008). Regarding the explanatory power, the coefficient of determination, $R^{2}$, suggests that the $\operatorname{AR}(1)$ model can explain about $13 \%$ of the variation in one-month holding gains on federal funds futures if the horizon is longer than two months.

We then compared this specification with a two-state Markov switching $\operatorname{AR}(1)(\operatorname{MSAR}(1))$ model:

$$
u_{n t}=\alpha_{n, s_{t}}+\phi_{n, s_{t}} u_{n, t-1}+\sigma_{n, s_{t}} \varepsilon_{t}, \varepsilon_{n t} \sim N(0,1),
$$

where $s_{t}$ is an unobserved latent variable presumed to follow a two-state firstorder Markov chain. The MLE reported in Table II identify two distinct regimes in fed funds futures prices. The first regime is characterized by a high risk premium $\left(\alpha_{n 1}>0\right)$ and high volatility $\left(\alpha_{n 1} \gg \alpha_{n 2}\right)$, while the second regime is associated with little risk premium and low volatility. Note that we fail to reject the null hypothesis of zero average risk premium in regime $2\left(\alpha_{n 2}=0\right)$ for every maturity $n$. 
TABLE II

Estimation Results for the MSAR(1) Model

\begin{tabular}{lcccccc}
\hline$n$ & 1 & 2 & 3 & 4 & 5 & 6 \\
\hline$p_{11}$ & 0.788 & 0.792 & 0.7920 & 0.937 & 0.935 & 0.937 \\
Std. error & 0.074 & 0.103 & 0.057 & 0.052 & 0.047 & 0.040 \\
$p_{22}$ & 0.840 & 0.9710 & 0.970 & 0.966 & 0.971 & 0.973 \\
Std. error & 0.047 & 0.042 & 0.019 & 0.027 & 0.019 & 0.017 \\
$\alpha_{1}$ & 7.15 & 11.9 & 9.83 & 10.3 & 21.8 & 24.1 \\
Std. error & 1.76 & 3.37 & 3.81 & 3.61 & 5.68 & 6.20 \\
$\alpha_{2}$ & -0.393 & 0.040 & 0.140 & -0.009 & -1.217 & -1.275 \\
Std. error & 0.291 & 0.512 & 0.697 & 1.040 & 1.221 & 1.552 \\
$\phi_{1}$ & -0.146 & 0.024 & 0.248 & 0.274 & 0.019 & -0.001 \\
Std. error & 0.120 & 0.132 & 0.157 & 0.126 & 0.158 & 0.154 \\
$\phi_{2}$ & 0.188 & 0.079 & 0.390 & 0.341 & 0.308 & 0.284 \\
Std. error & 0.060 & 0.063 & 0.067 & 0.094 & 0.082 & 0.088 \\
$\sigma_{1}$ & 13.4 & 20.8 & 23.5 & 24.2 & 24.0 & 26.5 \\
Std. error & 1.19 & 1.97 & 2.65 & 2.54 & 2.46 & 2.96 \\
$\sigma_{2}$ & 2.33 & 4.82 & 7.48 & 9.45 & 13.29 & 15.91 \\
Std. error & 0.25 & 0.44 & 0.52 & 0.83 & 0.95 & 1.08 \\
Log-likelihood & -613 & -675 & -716 & -758 & -793 & -822 \\
\hline
\end{tabular}

TABLE III

Hypothesis Testing Results of the Equality of Each Parameter Across Regimes for the MSAR(1) Model

\begin{tabular}{llcccccc}
\hline$n$ & & 1 & 2 & 3 & 4 & 5 & 6 \\
\hline$\alpha$ & Wald-stat & 17.9 & 12.1 & 6.21 & 7.85 & 16.0 & 15.9 \\
& $P$-value & 0.000 & 0.001 & 0.013 & 0.005 & 0.000 & 0.000 \\
$\phi$ & Wald-stat & 5.65 & 0.129 & 0.717 & 0.175 & 2.52 & 2.28 \\
& $P$-value & 0.017 & 0.720 & 0.397 & 0.675 & 0.112 & 0.131 \\
$\sigma$ & Wald-stat & 91.11 & 69.45 & 37.00 & 33.53 & 15.88 & 10.96 \\
& $P$-value & 0.000 & 0.000 & 0.000 & 0.000 & 0.000 & 0.001 \\
\hline
\end{tabular}

Table III reports tests of the hypothesis that parameters are constant across the two regimes. ${ }^{3}$ The differences in the constant term and volatility are highly significant for all horizons. On the other hand, the differences in the AR coefficient are not significant at the $10 \%$ significance level for any horizon longer than one month.

To assess the in-sample fit of the Markov switching models we use the Markov switching criterion (MSC) recently proposed by Smith, Naik, and Tsai

${ }^{3}$ Tests of the null hypothesis of no Markov switching are plagued by the problem that nuisance parameters are unidentified under the null. This is avoided here, insofar as the null hypothesis of constant coefficients still allows the regime transition probabilities to be identified from differences in variances, as in Engel and Hamilton (1990). 
TABLE IV

Comparison of Autoregressive Models

\begin{tabular}{|c|c|c|c|c|c|c|}
\hline$n$ & 1 & 2 & 3 & 4 & 5 & 6 \\
\hline \multicolumn{7}{|c|}{ Panel A: In-sample Markov Switching Criterion (MSC) } \\
\hline $\mathrm{AR}(1)$ & $1,565.05$ & $1,675.66$ & $1,714.84$ & $1,768.94$ & $1,819.94$ & $1,868.38$ \\
\hline $\operatorname{MSAR}(1)$ & $1,433.96$ & $1,557.92$ & $1,638.92$ & $1,722.84$ & $1,794.34$ & $1,850.75$ \\
\hline EGARCH-AR(1) & $1,421.57$ & $1,531.28$ & $1,633.79$ & $1,719.53$ & $1,795.68$ & $1,854.06$ \\
\hline $\mathrm{EGARCH}-\mathrm{AR}(1)\left(\phi_{n}=0\right)$ & $1,435.74$ & $1,551.53$ & $1,672.97$ & $1,760.72$ & $1,831.03$ & $1,886.88$ \\
\hline $\operatorname{EGARCH}-\operatorname{AR}(1)\left(\alpha_{n}=\phi_{n}=0\right)$ & $1,433.78$ & $1,550.41$ & $1,671.03$ & $1,759.03$ & $1,830.02$ & $1,887.29$ \\
\hline \multicolumn{7}{|c|}{ Panel B: Out-of-sample root mean squared error (RMSE) } \\
\hline $\operatorname{AR}(1)$ & 8.33 & 12.94 & 13.88 & 16.16 & 18.54 & 21.42 \\
\hline $\operatorname{MSAR}(1)$ & 7.95 & 12.78 & 13.40 & 15.64 & 17.40 & 20.57 \\
\hline EGARCH-AR(1) & 7.95 & 12.84 & 13.82 & 16.09 & 18.41 & 21.32 \\
\hline $\mathrm{EGARCH}-\mathrm{AR}(1)\left(\phi_{n}=0\right)$ & 8.06 & 12.83 & 15.02 & 17.66 & 19.96 & 22.34 \\
\hline $\operatorname{EGARCH}-\operatorname{AR}(1)\left(\alpha_{n}=\phi_{n}=0\right)$ & 8.15 & 13.28 & 15.55 & 18.26 & 20.76 & 23.27 \\
\hline \multicolumn{7}{|c|}{ Panel C: Statistical significance of out-of sample RMSE improvement } \\
\hline \multicolumn{7}{|l|}{$\operatorname{MSAR}(1)$ vs. $A R(1)$} \\
\hline CWtest statistic & 4.304 & 1.923 & 3.343 & 3.025 & 2.750 & 2.727 \\
\hline Approximate upper bound for $P$-value & 0.000 & 0.027 & 0.000 & 0.001 & 0.003 & 0.003 \\
\hline Monte Carlo $P$-value & 0.000 & 0.024 & 0.000 & 0.000 & 0.002 & 0.000 \\
\hline \multicolumn{7}{|l|}{ EGARCH-AR(1) vs. AR(1) CWtest statistic } \\
\hline CWtest statistic & 2.962 & 1.599 & 1.271 & 1.171 & 1.186 & 0.966 \\
\hline Approximate upper bound for $P$-value & 0.002 & 0.055 & 0.102 & 0.1 & 0.118 & 0.167 \\
\hline
\end{tabular}

(2006). The MSC asymptotically is a generalization of the Akaike Information Criterion. The MSC is based on the Kullback-Leibler divergence between the true and candidate models and is calculated as

$$
M S C=-2 \log (f(Y, \hat{\theta}))+\sum_{i=1}^{N} \frac{\hat{T}_{i}\left(\hat{T}_{i}+\lambda_{i} K\right)}{\delta_{i} \hat{T}_{i}-\lambda_{i} K-2},
$$

where $\log (f(Y, \hat{\theta}))$ is the maximized $\log$-likelihood value, $N$ is the number of regimes, $\hat{T}_{i}=\sum_{t=1}^{T} \hat{\xi}_{t i}, \hat{\xi}_{t i}$ is the smoothed probability of the regime $i$ at time $t, K$ is the number of regressors, and $\delta_{i}$ and $\lambda_{i}$ are tuning parameters. Following the suggestion of Smith et al. (2006), we set $\delta_{i}=1$ and $\lambda_{i}=N$. In our case, $N=2$ for the Markov-switching specifications and $N=1$ with no Markov-switching. The smaller the value for MSC, the better the model to be judged. The values for MSC given in Panel A of Table IV suggest that the MSAR(1) model would be selected over the $\operatorname{AR}(1)$ model for every horizon $n$.

We also compared models based on the out-of-sample root-mean-squared forecast errors (RMSE) on data since 2000 as follows. First, we estimated both 
AR(1) and MSAR(1) models using data from November 1990 to December 1999 and evaluated the terminal 1-month-ahead forecast error based on the estimation results. The data were then updated by 1 -month, and the terminal 1-month-ahead forecast error was re-calculated from the updated sample (specifically, from November 1990 to January 2000). This procedure was repeated until one month before the end of the sample period, namely May 2006. Panel B of Table IV reports the values of RMSE for the AR(1) and MSAR(1) models. As can be seen, the RMSE of the MSAR(1) model is uniformly smaller than that of the AR(1) model, meaning the MSAR(1) model provided better post-sample forecasts than the AR(1) model.

Are these differences in post-sample forecasting accuracy statistically significant? West (2006) noted the problems with testing the null hypothesis of no improvement in forecasting accuracy for situations like ours in which competing models are nested. Clark and West (2007) proposed a simple test appropriate for nested models constructed from the value of

$$
s_{t+1}=\hat{e}_{1, t+1}^{2}-\hat{e}_{2, t+1}^{2}+\left(\hat{y}_{1, t+1}-\hat{y}_{2, t+1}\right)^{2}
$$

where $\hat{y}_{1, t+1}$ is the forecast for date $t+1$ based on the more parsimonious model (in this case, the AR(1) model with no Markov switching) as estimated using observations through date $t, \hat{y}_{2, t+1}$ the forecast from the bigger model (in this case, the $\operatorname{MSAR}(1))$, and $\hat{e}_{i, t+1}=y_{t+1}-\hat{y}_{i, t+1}$ denote the respective forecast errors. The test statistic is essentially the usual $t$-statistic for testing whether $s$ has mean zero over the $P$ post-sample observations:

$$
\begin{aligned}
C W & =\frac{\sqrt{P^{-}}}{\sqrt{P^{-1} \sum_{t=R}^{R+P-1}\left(s_{t+1}-\bar{s}\right)^{2}}} \\
\bar{s} & =P^{-1} \sum_{t=R}^{R+P-1} s_{t+1} .
\end{aligned}
$$

Although the asymptotic distribution of $C W$ is unknown, Clark and West (2007) suggested that the $N(0,1)$ distribution gives a conservative approximation in the sense that if the null hypothesis is true (that is, if the parsimonious model is the correct one), then $C W$ should exceed the $N(0,1) 5 \%$ critical value (1.645) a little less than $5 \%$ of the time. We also performed a small Monte Carlo investigation of the accuracy of the Normal approximation in our setting. For each $n$, we generated 1,000 samples from the fitted $\operatorname{AR}(1)$ specification and recursively estimated on these generated samples $\operatorname{AR}(1)$ and $\operatorname{MSAR}(1)$ models from which the statistic $C W$ was calculated. We found that under the null hypothesis that the true data-generating process is an $\mathrm{AR}(1)$ with values equal 
to the estimated coefficients from the sample, the $C W$ statistic exceeded 1.645 with a probability between 0.027 (for $n=2$ ) and 0.048 (for $n=4$ ), confirming Clark and West's suggestion that the $N(0,1)$ distribution provides a good conservative approximation to the true test size.

The first row of Panel $\mathrm{C}$ of Table IV reports the Clark-West statistic $C W$ for testing the null hypothesis that the MSAR(1) offers no improvement in post-sample MSE over the simple $\operatorname{AR}(1)$. The second row reports an approximate upper bound for the $P$-value based on the Normal approximation, which indicates that the improvements in MSE are statistically significant in every case. The third row in Table IV C labeled Monte Carlo $P$-value is the fraction of times the generated statistic $C W$ exceeded the value obtained in the first row for the actual data for our 1,000 simulated $\mathrm{AR}(1)$ samples. These results confirm that the Markov-switching autoregression is a better model for forecasting holding gains.

Figure 1 plots the smoothed probabilities of regime 1 (high risk premium with high volatility regime). As was also reported by Bundick (2007), for the 1 -month contracts the moves in and out of regime 1 occur quite frequently, whereas regime 1 for the longer horizon contracts is associated with a few episodes of longer duration. Two of these occur before and following the recessions of 1990-1991 and 2001, and a third is associated with 1994-1995.

Figure 1 also plots gray regions for episodes in which the Fed was lowering its target for the fed funds rate. These dates also correlate with occurrences of regime 1 . The fact that $\alpha_{n 1}>0$ means that in regime 1 one could predict that $r_{t+n}$ will be lower on average than $f_{n t}$, or the fed funds market seems to underestimate the likelihood or magnitude of a funds rate cut at these times. On the other hand, although our model implies that the Fed will likely cut rates in these episodes, it also maintains that it is most difficult to predict interest rates at these times $\left(\alpha_{n 1} \gg \alpha_{n 2}\right)$. Interpreted as a risk premium, the claim is that at these times, holders of long-term bonds receive extra compensation for their risk, and this pricing of risk is mirrored in that those who take the long position in fed funds futures are rewarded on average for those positions.

Following Hamilton (2009, 2010), we also investigated whether the improved performance of the Markov-switching specifications results from its description of the conditional variance rather than the conditional mean. We generalized the baseline autoregression (7) to allow for outliers and heteroskedasticity, using an $\operatorname{EGARCH}(1,1)$ specification with a time trend ${ }^{4}$ in the variance,

$$
u_{n t}=\alpha_{n}+\phi_{n} u_{n, t-1}+e_{n t}
$$

${ }^{4}$ As in Hamilton (2009), we scaled the time trend by dividing by 1,000 for better numerical stability. 


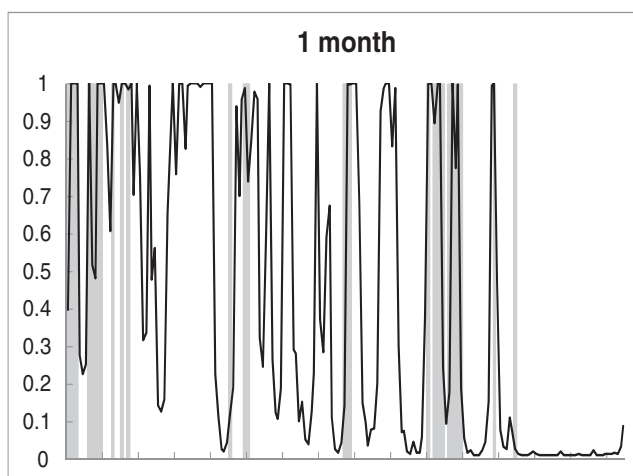

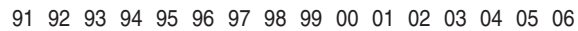
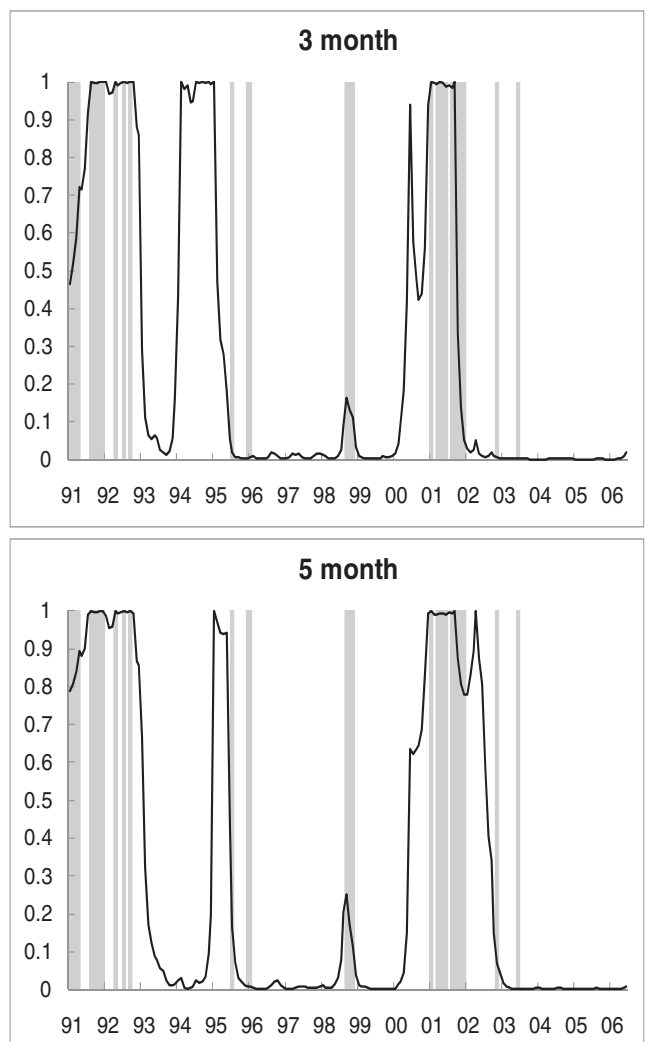

2 month

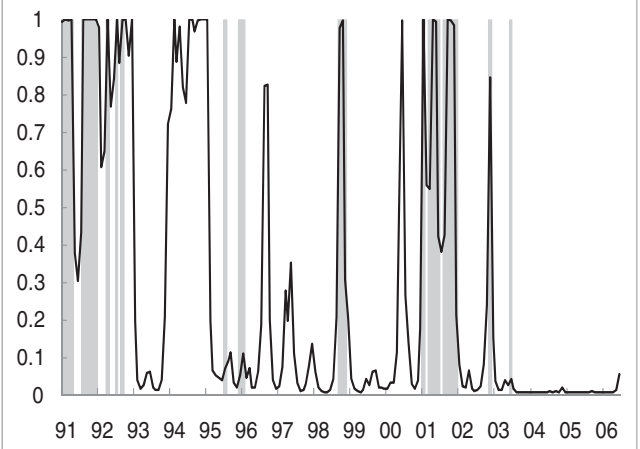

4 month

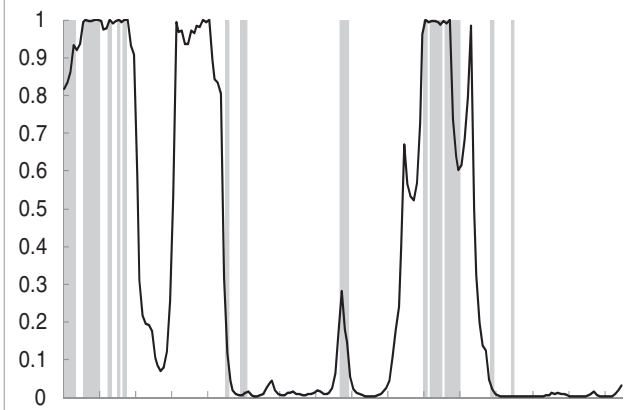

$\begin{array}{llllllllllllllll}91 & 92 & 93 & 94 & 95 & 96 & 97 & 98 & 99 & 00 & 01 & 02 & 03 & 04 & 05 & 06\end{array}$

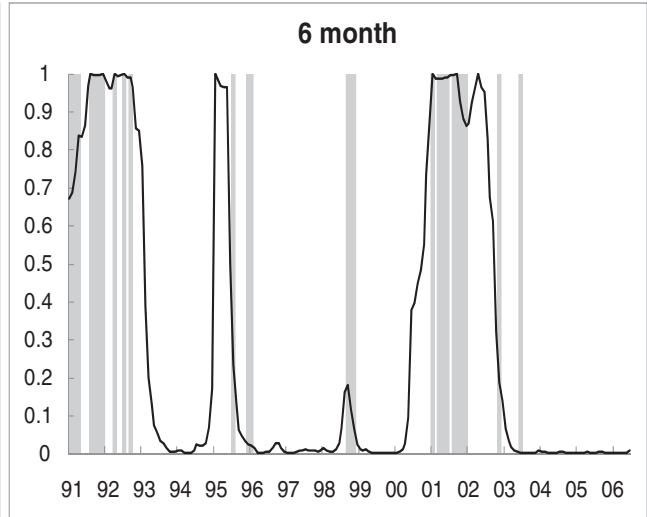

FIGURE 1

Smoothed probabilities for the high risk premium and volatility regime based on the MSAR(1) model. 
TABLE V

Estimation Results for the AR(1)-EGARCH Model

\begin{tabular}{lcccccc}
\hline$n$ & 1 & 2 & 3 & 4 & 5 & 6 \\
\hline$\alpha$ & -0.118 & -0.333 & -0.089 & 0.674 & 1.066 & 1.749 \\
Std. error & 0.243 & 0.332 & 0.612 & 0.815 & 1.208 & 1.317 \\
$\phi$ & 0.096 & 0.162 & 0.354 & 0.373 & 0.382 & 0.366 \\
Std. error & 0.066 & 0.054 & 0.056 & 0.057 & 0.057 & 0.059 \\
$Y$ & 4.85 & 5.52 & 5.60 & 5.61 & 5.89 & 6.09 \\
Std. error & 0.45 & 0.43 & 0.42 & 0.36 & 0.38 & 0.32 \\
$\delta$ & 0.600 & 0.88 & 0.8280 & 0.879 & 0.893 & 0.895 \\
Std. error & 0.181 & 0.171 & 0.078 & 0.096 & 0.099 & 0.134 \\
$\eta$ & 0.188 & 0.109 & 0.10 & 0.076 & 0.049 & 0.034 \\
Std. error & 0.072 & 0.064 & 0.068 & 0.065 & 0.053 & 0.065 \\
$\xi$ & -23.2 & -23.9 & -15.3 & -9.78 & -7.18 & -5.97 \\
Std. error & 3.93 & 4.11 & 3.82 & 3.11 & 3.02 & 2.77 \\
$\nu$ & 2.05 & 2.08 & 3.07 & 3.42 & 4.07 & 4.12 \\
Std. error & 0.43 & 0.44 & 0.76 & 0.83 & 1.25 & 1.19 \\
Log-likelihood & -610 & -665 & -717 & -759 & -798 & -827 \\
\hline & & & & & &
\end{tabular}

with $e_{n t}$ drawn from a Student $t$ distribution with $\nu_{n}$ degrees of freedom and scale parameter $h_{n t}$ evolving according to ${ }^{5}$

$\log h_{n t}-\gamma_{n}-\xi_{n} t=\delta\left[\log h_{n, t-1}-\gamma_{n}-\xi_{n}(t-1)\right]+\eta_{n}\left(\left|e_{n, t-1} / h_{n, t-1}\right|-k_{\nu_{n}}\right)$.

Estimates for the parameters are reported in Table V. Consistent with the results in Hamilton (2009), when heteroskedasticity and fat tails are allowed for in the estimation, the intercept $\alpha_{n}$ for $n=1-3$ changes signs and is no longer statistically significant. The autoregressive parameter is statistically significant for $n \geq 2$ but not for $n=1$. As seen in row 3 of Table IVA, the EGARCH-AR(1) specification (10)-(11) has a better in-sample fit in terms of the Markov Switching Criterion for $n=1-4$, while the Markov-switching specification (8) does better at horizons 5 and 6. The success of the Markov-switching specification for short horizons relative to the homoskedastic Gaussian AR(1) thus results in part from its description of a time-varying variance, which might be more parsimoniously captured with an EGARCH specification. For the longer horizons, however, the broad episodes of predictability described by the Markov-switching model appear to be a genuine feature of the data.

${ }^{5}$ Here $k_{\nu_{n}}$ represents the expected absolute value for a Student $t$ variable with $\nu_{n}$ degrees of freedom:

$$
k_{\nu_{n}}=\frac{2 \sqrt{\nu_{n}} \Gamma\left[\left(\nu_{n}+1\right) / 2\right]}{\left(\nu_{n}-1\right) \sqrt{\pi} \Gamma\left(\nu_{n} / 2\right)} .
$$


In row 3 of Table IVB we compare the EGARCH-AR(1) specification with the others in terms of the post-sample forecasts. The EGARCH specification does as well as Markov-switching for $n=1$, while the MS models do uniformly better than EGARCH at longer horizons. The last row of Table IVC shows that the EGARCH specification yields statistically significantly better forecasts than the simple $\mathrm{AR}(1)$ only for the $n=1$ horizon.

We also estimated more restricted versions of the EGARCH specification that imposed a constant risk premium $\left(\phi_{n}=0\right)$ or zero risk premium $\left(\alpha_{n}=\phi_{n}=0\right)$. Both in sample and out of sample these tend to be dominated by both the unrestricted EGARCH-AR(1) and the Markov-switching AR(1).

\section{Predictive Regression Models}

We now explore the role of a set of other variables besides lagged gains that might help predict holding gains on fed funds contracts. We use the set of variables proposed by Piazzesi and Swanson $(2004,2008)$ and also used by Hamilton (2009). These explanatory variables include the employment growth rate, the credit spread, and assorted treasury yield spreads. For employment growth we looked at two measures. The first is the 12-month change in the logarithm of seasonally adjusted nonfarm payrolls for the period ended in month $t-2$. Although a value for this number would have been known to market participants as of the end of month $t-1$, the currently revised series is not the same as the number actually available at the time. We therefore also conducted these tests using the 12-month growth in seasonally unadjusted nonfarm payrolls as reported at the time from the real-time data set of the Federal Reserve Bank of Philadelphia.

Our measure for the credit spread is the difference between Baa-corporate and 10-year treasury yields (in basis points). We also used four different treasury spreads based on the differences of the 6-month, 1-, 2-, 5-, and 10-year treasury yields for month $t-1$. All data other than the real-time employment series were obtained from the FRED database of the Federal Reserve Bank of St. Louis.

We explored the role of the above list of explanatory variables, taken one at a time, in predictive regressions for three sets of specifications. The first is a homoskedastic Gaussian regression:

$$
u_{n t}=\alpha_{n}+\phi_{n} u_{n, t-1}+\beta_{n} x_{t-1}+\sigma_{n} \varepsilon_{n t}, \varepsilon_{n t} \sim \mathrm{N}(0,1) .
$$

We compared this with a Markov-switching predictive regression (MSPR),

$$
u_{n t}=\alpha_{n, s_{t}}+\phi_{n, s_{t}} u_{n, t-1}+\beta_{n, s_{t}} x_{t-1}+\sigma_{n, s_{t}} \varepsilon_{n t}, \varepsilon_{n t} \sim N(0,1)
$$




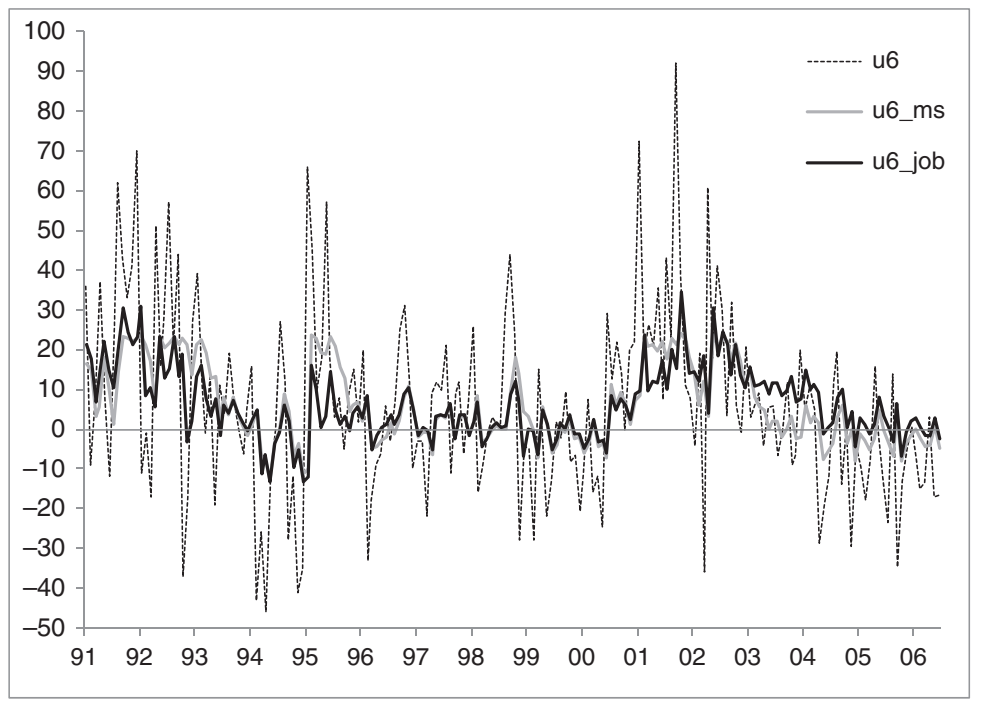

FIGURE 2

Comparison of the predicted values from the MSAR model and predictive regression for 6-month futures contracts. Dotted line: observed value of $u_{6 t}$ for each month $t$. Bold line: predicted value of $u_{6 t}$ based on information available as of month $t-1$ using the predictive regression based on growth in nonfarm payrolls. Gray line: predicted value of $u_{6 t}$ based on information available as of month $t-1$ using Markovswitching autoregression and no other explanatory variables.

and a predictive regression with EGARCH Student $t$ errors,

$$
u_{n t}=\alpha_{n}+\phi_{n} u_{n, t-1}+\beta_{n} x_{t-1}+e_{n t}
$$

where $e_{n t}$ is drawn from a Student $t$ distribution with $\nu_{n}$ degrees of freedom and scale parameter $h_{n t}$ evolving according to (11).

Figure 2 illustrates the difference between the predictions of the Markovswitching formulation with no explanatory variables (8) and the simple predictive regression (12) for the case when employment growth is the explanatory variable and $n=6$. The actual 1 -month gain from taking the long position in a 6-month fed funds futures contract at the end of month $t-1$ and closing the position at the end of month $t$ is plotted as the dotted line. The predicted gain as of time $t-1$ according to the Markov-switching specification is given by the gray line, while that from the homoskedastic predictive regression is shown in bold. The two formulations are both capturing the tendency for there to be bigger gains in the early 1990s and early 2000s, the predictive regression because these were episodes of falling employment, and the Markov-switching model because they were identified as associated with regime 1 . The latter does a better job of recognizing the shift in 2003 to a regime in which there were no longer expected gains associated with these contracts. 
Ferrero and Nobili (2009) raised concerns about the stability of predictive regressions like these, although this may be less significant for our specifications and sample than for the ones they explored. Following Piazzesi and Swanson (2008), we estimated the specifications (12) and (13) for a sample that begins in November 1990 and ends in month $R$ for every date $R$ between July 1996 and June 2006. The top panel of Figure 3 compares the forecast for each $R$ from this rolling predictive regression with the full-sample regression for $x_{t-1}$ corresponding to the 12-month employment growth measure and $n=4$. The forecasts are similar and do not differ much over the sample. The middle panel compares a rolling Markov-switching predictive regression with the fullsample Markov-switching predictive regression, which again do not differ much. The bottom panel compares rolling-sample and full-sample forecasts from the simple MSAR specification (8) with no explanatory variables, which are often quite close. ${ }^{6}$

Comparisons among the different predictive regression specifications based on the in-sample MSC are reported in Table VI. For every $n$, the Markov-switching model with no explanatory variables is seen in the second row of Table IVA to achieve better MSC than any predictive regression using any explanatory variable in Table VIA. In fact, for the $n=6$ case, the Markovswitching autoregression does better than any Markov-switching or EGARCH predictive regression using any explanatory variable, with the single exception of the Markov-switching regression based on the 1-year minus 6-month spread. The Markov-switching autoregression also performs well among this group at predicting the 5-month contract gains, but for shorter horizons it tends to be dominated by the EGARCH predictive regressions. More generally, we can make the following observations from the results in Table VI. First, for every explanatory variable and every horizon, the Gaussian predictive regression (12) is dominated by both the Markov-switching and EGARCH predictive regressions. Second, for most explanatory variables and horizons, the EGARCH predictive regressions do better than the Markov-switching predictive regressions.

In comparing across explanatory variables and specifications, for horizons 5 and 6 the Markov-switching predictive regression based on the 1-year minus 6-month treasury spread has the best fit to the data, while for horizons 2 and 3 , an EGARCH specification based on this same variable does best. For $n=1$, an EGARCH formulation based on the 2-year minus the 1-year spread does best,

\footnotetext{
${ }^{6}$ Note that the most significant instability found in the tests reported in Table AI in Ferrero and Nobili (2009) comes from the specifications with their $n$ greater than 3 quarters, whereas the longest specification we consider uses 6-month contracts. Ferrero and Nobili's decomposition of excess returns into a risk premium and forecast error is also very interesting, although lack of monthly-horizon survey data for our full sample makes it infeasible to replicate their approach in our setting.
} 

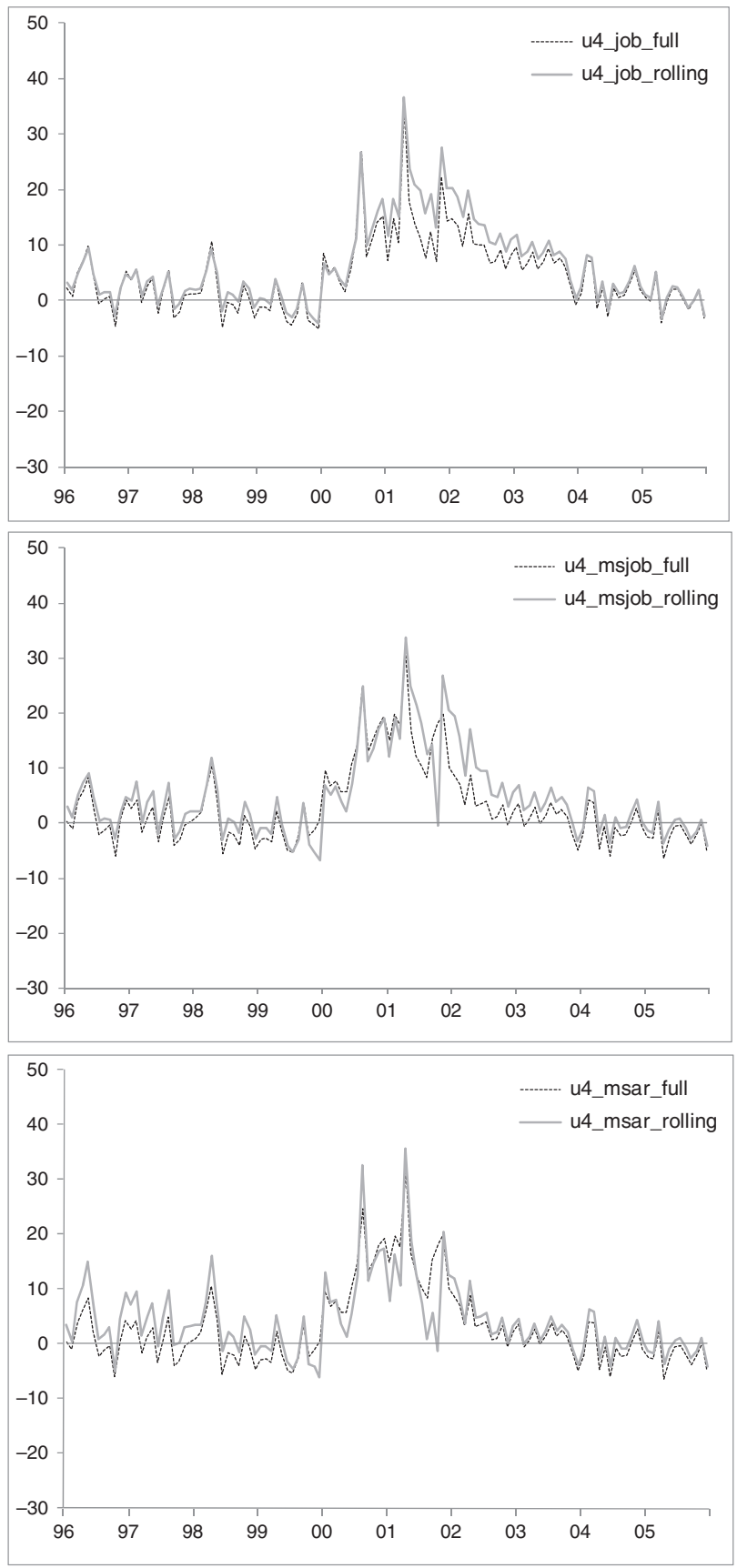

FIGURE 3

Rolling-sample versus full-sample comparison of predicted holding returns on 4-month contract from predictive regression based on employment growth, from Markov-switching predictive regression based on employment growth, and from Markov-switching autoregression. Top panel: solid line is the forecast of employment-based predictive regression (12) estimated from a rolling sample ending at the indicated date, while dotted line is forecast of same model using the full sample of data. Middle panel: solid line is

forecast of Markov-switching employment-based predictive regression (13) estimated from a rolling sample ending at the indicated date, while dotted line is forecast of same model using the full sample of data. Bottom panel: solid line is forecast of Markov-switching autoregression (8) using a rolling sample ending at the indicated date, while dotted line is forecast of same model using the full sample. 
TABLE VI

Comparison of Predictive Regressions Based on In-sample MSC

\begin{tabular}{lcccccc}
\hline$n$ & 1 & 2 & 3 & 4 & 5 & 6 \\
\hline Panel A: Homoskedastic & & & & & & \\
12-month job growth & & & & & \\
Real-time 12-month job growth & $1,566.26$ & $1,673.13$ & $1,711.58$ & $1,764.43$ & $1,815.35$ & $1,863.12$ \\
Baa minus 10-year treasury spread & $1,566.54$ & $1,674.70$ & $1,713.64$ & $1,766.93$ & $1,817.81$ & $1,865.49$ \\
10-year minus 5-year treasury spread & $1,567.01$ & $1,676.79$ & $1,716.21$ & $1,770.27$ & $1,821.27$ & $1,869.73$ \\
5-year minus 2-year treasury spread & $1,567.02$ & $1,677.64$ & $1,716.68$ & $1,770.82$ & $1,821.83$ & $1,870.39$ \\
2-year minus 1-year treasury spread & $1,566.29$ & $1,677.71$ & $1,716.82$ & $1,770.66$ & $1,821.50$ & $1,869.40$ \\
1-year minus 6-month treasury spread & $1,567.10$ & $1,677.03$ & $1,716.81$ & $1,770.98$ & $1,821.78$ & $1,869.90$ \\
Panel B: Markov-switching & & & & & & \\
12-month job growth & & & & & & \\
Real-time 12-month job growth & $1,439.27$ & $1,558.97$ & $1,643.92$ & $1,728.14$ & $1,801.18$ & $1,858.37$ \\
Baa minus 10-year treasury spread & $1,441.06$ & $1,561.91$ & $1,646.36$ & $1,730.29$ & $1,802.20$ & $1,859.26$ \\
10-year minus 5-year treasury spread & $1,442.78$ & $1,560.77$ & $1,645.47$ & $1,730.43$ & $1,803.21$ & $1,859.45$ \\
5-year minus 2-year treasury spread & $1,443.24$ & $1,566.31$ & $1,647.51$ & $1,730.70$ & $1,801.81$ & $1,857.21$ \\
2-year minus 1-year treasury spread & $1,439.64$ & $1,563.01$ & $1,646.64$ & $1,729.55$ & $1,800.77$ & $1,860.16$ \\
1-year minus 6-month treasury spread & $1,438.48$ & $1,559.17$ & $1,632.84$ & $1,722.93$ & $1,793.31$ & $1,852.81$ \\
Panel C: EGARCH & & & & & $1,789.70$ & $1,632.841$ \\
12-month job growth & & & & & & \\
Real-time 12-month job growth & $1,633.5$ & $1,533.39$ & $1,633.55$ & $1,718.55$ & $1,794.34$ & $1,852.41$ \\
Baa minus 10-year treasury spread & $1,423.63$ & $1,533.43$ & $1,634.93$ & $1,719.92$ & $1,795.81$ & $1,853.85$ \\
10-year minus 5-year treasury spread & $1,423.23$ & $1,533.44$ & $1,635.71$ & $1,721.58$ & $1,797.41$ & $1,855.77$ \\
5-year minus 2-year treasury spread & $1,423.75$ & $1,532.84$ & $1,635.41$ & $1,721.59$ & $1,797.85$ & $1,856.24$ \\
2-year minus 1-year treasury spread & $1,420.76$ & $1,525.05$ & $1,629.78$ & $1,719.69$ & $1,796.38$ & $1,854.72$ \\
1-year minus 6-month treasury spread & $1,421.97$ & $1,524.99$ & $1,629.40$ & $1,716.84$ & $1,793.01$ & $1,851.49$ \\
- & & & & $1,795.75$ & $1,854.79$ \\
\hline
\end{tabular}

while for $n=4$, EGARCH using 2-year minus 1-year does about the same as Markov-switching using 1-year minus 6-month.

Table VII reports the estimated values for $\beta_{n 1}$ and $\beta_{n 2}$ for each of the Markov-switching predictive regressions. With the exception of the last two term spreads, the estimated value for $\beta_{n 2}$ is always statistically indistinguishable from zero, reinforcing our conclusion that the main evidence for predictable holding yields comes from regime 1. In fact, something similar in practice is implied even for the term spread specifications in which $\beta_{n 1}$ is often negative and $\beta_{n 2}$ is positive and sometimes statistically significant.

Table VIII reports the full parameter estimates for the Markov-switching predictive regressions based on the 1 -year minus 6-month spread. Using the $n=5$ results for illustration, the net contribution of the intercept and spread is positive on average in regime 1 ,

$$
\alpha_{51}+\beta_{51} \bar{s}_{1 y, 6 m}=15.8-(0.186)(17.6)=12.5
$$


TABLE VII

Estimated Coefficients on the Explanatory Variable for the MSPR Models

\begin{tabular}{|c|c|c|c|c|c|c|c|}
\hline$n$ & & 1 & 2 & 3 & 4 & 5 & 6 \\
\hline 12-month job growth & $\begin{array}{l}\beta_{1} \\
\text { Std. error } \\
\beta_{2} \\
\text { Std. error }\end{array}$ & $\begin{array}{r}-5.097 \\
2.817 \\
0.363 \\
0.472\end{array}$ & $\begin{array}{r}-13.853 \\
4.852 \\
0.878 \\
0.868\end{array}$ & $\begin{array}{r}-10.686 \\
5.495 \\
-0.957 \\
1.171\end{array}$ & $\begin{array}{r}-8.436 \\
4.554 \\
-1.648 \\
2.001\end{array}$ & $\begin{array}{r}2.659 \\
5.762 \\
-4.410 \\
2.777\end{array}$ & $\begin{array}{r}3.043 \\
6.239 \\
-4.615 \\
3.251\end{array}$ \\
\hline $\begin{array}{l}\text { Real-time 12-month } \\
\text { job growth }\end{array}$ & $\begin{array}{l}\beta_{1} \\
\text { Std. error } \\
\beta_{2} \\
\text { Std. error }\end{array}$ & $\begin{array}{r}-1.882 \\
1.525 \\
0.135 \\
0.231\end{array}$ & $\begin{array}{r}-5.160 \\
2.315 \\
0.510 \\
0.400\end{array}$ & $\begin{array}{r}-3.719 \\
2.732 \\
-0.259 \\
0.625\end{array}$ & $\begin{array}{r}-2.912 \\
2.366 \\
-0.547 \\
0.964\end{array}$ & $\begin{array}{r}1.888 \\
2.885 \\
-1.582 \\
1.401\end{array}$ & $\begin{array}{r}1.914 \\
2.558 \\
-1.499 \\
1.246\end{array}$ \\
\hline $\begin{array}{l}\text { Baa minus 10-year } \\
\text { treasury spread }\end{array}$ & $\begin{array}{l}\beta_{1} \\
\text { Std. error } \\
\beta_{2} \\
\text { Std. error }\end{array}$ & $\begin{array}{r}0.045 \\
0.024 \\
-0.006 \\
0.005\end{array}$ & $\begin{array}{r}0.113 \\
0.052 \\
-0.014 \\
0.009\end{array}$ & $\begin{array}{r}0.128 \\
0.071 \\
-0.002 \\
0.012\end{array}$ & $\begin{array}{r}0.099 \\
0.080 \\
-0.003 \\
0.017\end{array}$ & $\begin{array}{r}-0.029 \\
0.063 \\
0.014 \\
0.025\end{array}$ & $\begin{array}{r}-0.052 \\
0.066 \\
0.018 \\
0.031\end{array}$ \\
\hline $\begin{array}{l}\text { 10-year minus } 5 \text {-year } \\
\text { treasury spread }\end{array}$ & $\begin{array}{l}\beta_{1} \\
\text { Std. error } \\
\beta_{2} \\
\text { Std. error }\end{array}$ & $\begin{array}{r}-0.016 \\
0.056 \\
-0.004 \\
0.007\end{array}$ & $\begin{array}{r}-0.059 \\
0.107 \\
-0.011 \\
0.013\end{array}$ & $\begin{array}{r}-0.128 \\
0.128 \\
0.005 \\
0.019\end{array}$ & $\begin{array}{r}-0.142 \\
0.132 \\
0.009 \\
0.023\end{array}$ & $\begin{array}{r}-0.312 \\
0.142 \\
-0.013 \\
0.035\end{array}$ & $\begin{array}{r}-0.294 \\
0.153 \\
-0.020 \\
0.040\end{array}$ \\
\hline $\begin{array}{l}\text { 5-year minus 2-year } \\
\text { treasury spread }\end{array}$ & $\begin{array}{l}\beta_{1} \\
\text { Std. error } \\
\beta_{2} \\
\text { Std. error }\end{array}$ & $\begin{array}{l}0.002 \\
0.033 \\
0.000 \\
0.005\end{array}$ & $\begin{array}{r}-0.054 \\
0.069 \\
-0.003 \\
0.009\end{array}$ & $\begin{array}{r}-0.070 \\
0.075 \\
0.013 \\
0.014\end{array}$ & $\begin{array}{r}-0.061 \\
0.066 \\
0.026 \\
0.019\end{array}$ & $\begin{array}{r}-0.054 \\
0.060 \\
0.040 \\
0.024\end{array}$ & $\begin{array}{r}-0.142 \\
0.102 \\
0.006 \\
0.030\end{array}$ \\
\hline $\begin{array}{l}\text { 2-year minus 1-year } \\
\text { treasury spread }\end{array}$ & $\begin{array}{l}\beta_{1} \\
\text { Std. error } \\
\beta_{2} \\
\text { Std. error }\end{array}$ & $\begin{array}{r}-0.004 \\
0.055 \\
0.019 \\
0.011\end{array}$ & $\begin{array}{r}-0.204 \\
0.114 \\
0.019 \\
0.017\end{array}$ & $\begin{array}{c}-0.168 \\
0.114 \\
0.060 \\
0.0\end{array}$ & $\begin{array}{r}-0.133 \\
0.095 \\
0.129 \\
0.044\end{array}$ & $\begin{array}{r}-0.112 \\
0.099 \\
0.197 \\
0.054\end{array}$ & $\begin{array}{r}-0.072 \\
0.115 \\
0.253 \\
0.073\end{array}$ \\
\hline $\begin{array}{l}\text { 1-year minus 6-month } \\
\text { treasury spread }\end{array}$ & $\begin{array}{l}\beta_{1} \\
\text { Std. error } \\
\beta_{2} \\
\text { Std. error }\end{array}$ & $\begin{array}{r}-0.076 \\
0.076 \\
0.035 \\
0.024\end{array}$ & $\begin{array}{r}-0.313 \\
0.160 \\
0.054 \\
0.032\end{array}$ & $\begin{array}{c}-0.206 \\
0.1310 \\
0.196 \\
0.050\end{array}$ & $\begin{array}{r}-0.200 \\
0.123 \\
0.267 \\
0.064\end{array}$ & $\begin{array}{r}-0.186 \\
0.131 \\
0.331 \\
0.086\end{array}$ & $\begin{array}{r}-0.148 \\
0.150 \\
0.412 \\
0.110\end{array}$ \\
\hline
\end{tabular}

for $\bar{s}_{1 y, 6 m}=17.6$ the average 1 -year minus 6 -month spread. If the spread is above its average value, the expected value of $u_{5 t}$ would be less than $12.5-\mathrm{a}$ more steeply sloped yield curve lessens the expected profitability of a long position in 5-month fed funds futures in this regime. By contrast, the typical expected drift in regime 2 is essentially zero, just as it was in the simple MSAR formulation:

$$
\alpha_{52}+\beta_{52} \bar{s}=-6.4+(0.33)(17.6)=-0.6 \text {. }
$$

In this case, if the yield curve becomes more steeply sloped than average, it suggests that there is a small profit opportunity from taking a long position in fed funds futures. Figure 4 displays the difference between the predicted values from MSAR (8) and MSPR (13) for the case $n=5$. 
TABLE VIII

Estimation Results for the MSPR Model ( $1 \mathrm{y}-6 \mathrm{~m}$ Treasury Yield Spread)

\begin{tabular}{lcccccc}
\hline$n$ & 1 & 2 & 3 & 4 & 5 & 6 \\
\hline$p_{11}$ & 0.796 & 0.800 & 0.933 & 0.938 & 0.947 & 0.945 \\
Std. error & 0.071 & 0.096 & 0.038 & 0.035 & 0.032 & 0.031 \\
$p_{22}$ & 0.841 & 0.918 & 0.966 & 0.962 & 0.962 & 0.958 \\
Std. error & 0.048 & 0.038 & 0.019 & 0.019 & 0.019 & 0.021 \\
$\alpha_{1}$ & 8.72 & 19.9 & 14.26 & 15.1 & 15.8 & 15.7 \\
Std. error & 2.38 & 5.59 & 4.30 & 4.62 & 4.91 & 4.96 \\
$\alpha_{2}$ & -0.969 & -0.739 & -3.68 & -4.81 & -6.39 & -8.18 \\
Std. error & 0.498 & 0.650 & 1.13 & 1.42 & 1.78 & 2.62 \\
$\phi_{1}$ & -0.131 & -0.071 & 0.164 & 0.196 & 0.197 & 0.210 \\
Std. error & 0.112 & 0.158 & 0.143 & 0.128 & 0.127 & 0.116 \\
$\phi_{2}$ & 0.096 & 0.094 & 0.311 & 0.314 & 0.260 & 0.210 \\
Std. error & 0.145 & 0.061 & 0.078 & 0.069 & 0.092 & 0.102 \\
$\beta_{1}$ & -0.076 & -0.313 & -0.206 & -0.1860 & -0.186 & -0.148 \\
Std. error & 0.076 & 0.160 & 0.1310 & 0.123 & 0.131 & 0.150 \\
$\beta_{2}$ & 0.035 & 0.054 & 0.196 & 0.267 & 0.331 & 0.412 \\
Std. error & 0.024 & 0.032 & 0.0 & 0.064 & 0.086 & 0.110 \\
$\sigma_{1}$ & 13.3 & 20.0 & 21.6 & 23.2 & 24.8 & 27.5 \\
Std. error & 1.16 & 2.10 & 2.19 & 2.11 & 2.08 & 2.39 \\
$\sigma_{2}$ & 2.26 & 4.86 & 6.70 & 8.47 & 10.7 & 12.7 \\
Std. error & 0.24 & 0.42 & 0.48 & 0.64 & 0.80 & 1.01 \\
Log-likelihood & -611 & -671 & -708 & -749 & -786 & -816 \\
\hline
\end{tabular}

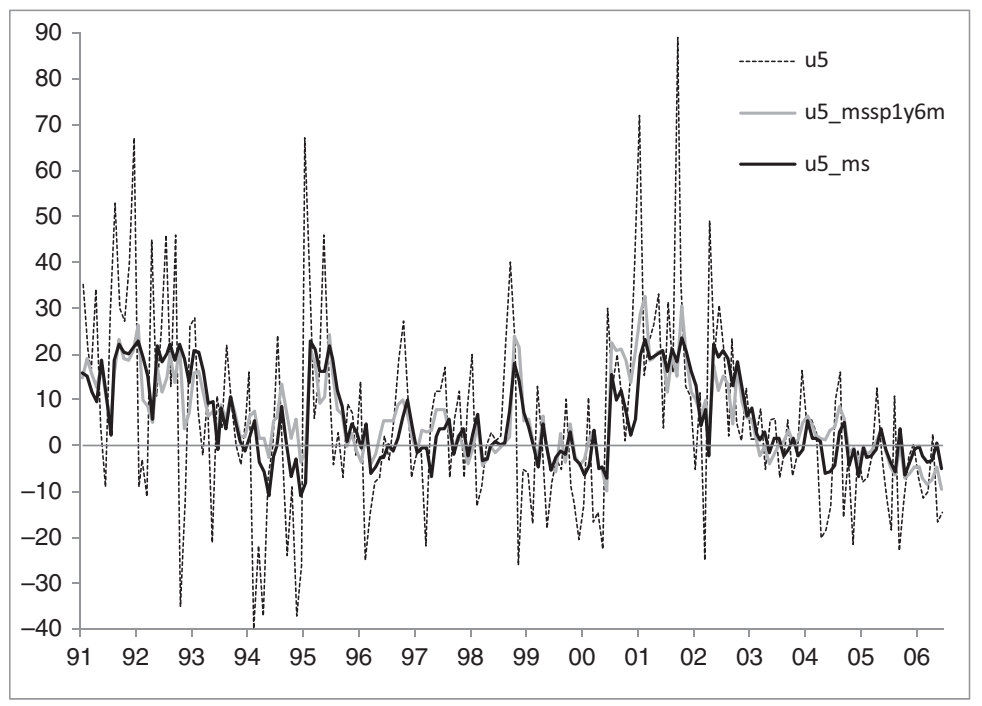

FIGURE 4

Comparison of the predicted values from the MSAR and MSPR models for 5-month futures contracts. Dotted line: observed value of $u_{5 t}$ for each month $t$. Bold line: predicted value of $u_{5 t}$ based on information available as of month $t-1$ using Markov-switching autoregression and no other explanatory variables.

Gray line: predicted value of $u_{5 t}$ based on information available as of month $t-1$ using Markovswitching predictive regression autoregression based on 1-year minus 6-month spread. 
Table IX reports the post-sample root-mean-square errors for the various predictive regressions estimated. Predictive EGARCH regressions based on employment growth do best for the 1- and 2-month contracts, while predictive Markov-switching regressions using the $1 \mathrm{y}-6 \mathrm{~m}$ or $10 \mathrm{y}-5 \mathrm{y}$ spreads do best for the 3- to 6-month contracts among the predictive regressions. The MSAR specification turns out to dominate all other models for $n=5$ in terms of postsample performance. Panels B and C of Table IX also report approximate $P$-values (based on the $N(0,1)$ approximation to the Clark-West test statistic (9)) for the test of the null hypothesis that the forecast in Panel $\mathrm{B}$ or $\mathrm{C}$ is no better than the corresponding entry in Panel A. The forecast im-provement of the Markovswitching predictive regression over the homoskedastic predictive regressions is statistically significant in almost all cases. The improvement of the EGARCH predictive regression over the homoskedastic predictive regression is statistically significant in $2 / 3$ of the cases.

\section{APPLICATION: INTERPRETING FED FUNDS FUTURES IN JULY 2009}

We illustrate some implications and potential uses of these estimates by taking a look at fed funds futures prices in the summer of 2009. During the first half of 2009, the Fed had announced a target range for the fed funds rate of between 0 and 25 basis points. The actual average monthly fed funds rate was between 15 and 22 basis points over these 6 months, averaging $18 \mathrm{bp}$.

The interest rates implied by fed funds futures contracts as of June 30 are plotted as the solid line in Figure 5. These rise steadily to a value of 35 basis points for the December contract. Some analysts had interpreted that modest slope to a belief by traders that there was some possibility that the Fed could increase its target before the end of the year, despite statements from Fed officials that seemed to suggest such a change was unlikely.

To what extent is it plausible to attribute this slope instead to the pricing of risk implicit in these contracts? One quick way to answer this question is to look at the average historical discrepancy between the fed funds futures contract and what the actual interest rate turned out to be. The average value of $u_{1 t}$ in our sample is 2.9 basis points, from which, as in Piazzesi and Swanson (2008), one might calculate a risk-adjusted market forecast that is 2.9 basis points below the 1 -month fed funds futures rate $f_{1 t}$. The average value of $u_{2 t}$ is 6.9 , implying that $f_{2 t}$ exceeded $r_{t+2}$ on average by $2.9+6.9=9.8$ basis points, for a risk-adjusted implied forecast of $f_{2 t}-9.8$.

The dashed line in Figure 5 uses these calculations to calculate what we would expect the fed funds futures rate to be as of June 30, 2009 if investors in fact believed that the actual rate each month would be the same 18 basis points 


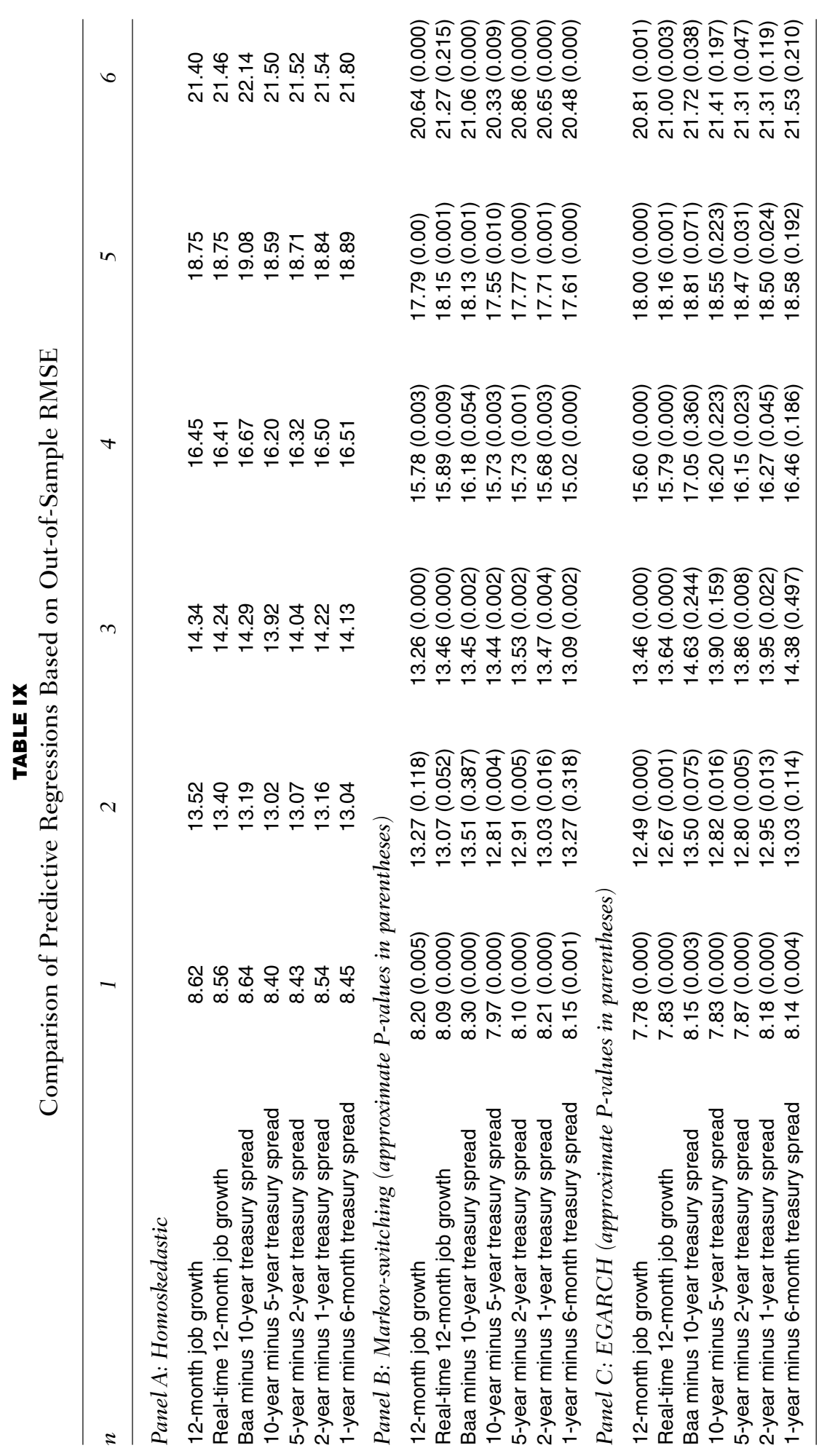




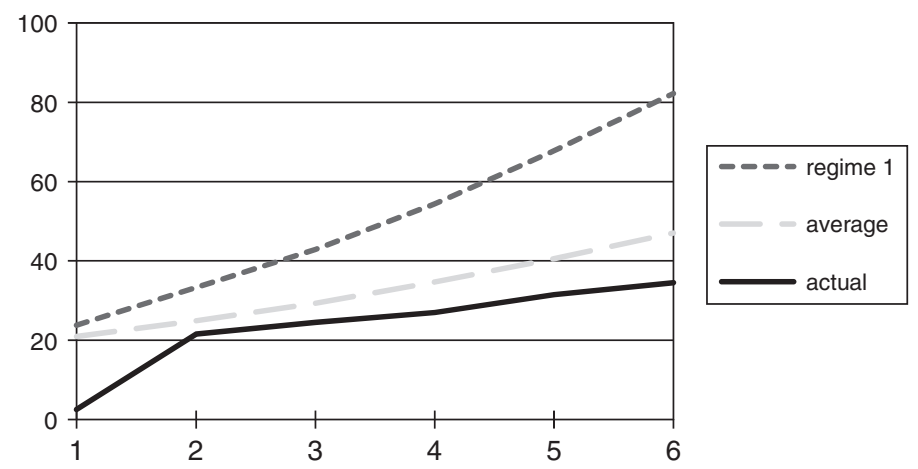

FIGURE 5

Predicted interest rates on fed funds futures contracts as of June 30, 2009 under alternative scenarios, in basis points. Average: implied fed funds futures rate if market expects fed funds rate to remain at 18 basis points through the end of 2009 but futures contracts embody historical average risk premia. Regime 1: market expects fed funds rate to remain at 18 basis points through the end of 2009 but futures contracts embody risk premia appropriate if June 2009 is known to have been governed by regime 1. Actual: actual fed funds futures rates on June 30, 2009.

observed in the first half of the year, but these contracts incorporated risk premia consistent with their average ex post gains on fed funds contracts of different maturities. Such a calculation suggests that the modest upward slope in fed funds futures in the summer of 2009 is fully consistent with a belief by market participants that the actual fed funds rate was unlikely to change.

Our Markov-switching framework suggests that average pricing of risk over the entire sample in fact arises from a few episodes associated with weak economic activity and highly volatile interest rates in which the risk premium was quite large. Conditions in 2009 are clearly outside of the range included in the sample, both in the severity of the economic downturn and in the fact that the fed funds rate had effectively bumped against the zero lower bound, which is why we did not attempt to use these data in the estimation. However, it is interesting to take a look at what the model would imply if we assumed that the economy was in regime 1 in June of 2009 and that the 1 -year minus 6-month spread at that time ( 21 basis points) was expected to persist through the end of the year.

Let

$$
\begin{aligned}
& \hat{u}_{n, t+j t}\left(i_{k}, i_{k-1}, \ldots, i_{1}\right) \\
& \quad=E\left(u_{n, t+j} \mid u_{n t}, s_{t+k}=i_{k}, s_{t+k-1}=i_{k-1}, \ldots, s_{t+1}=i_{1}, s_{t}=1\right)
\end{aligned}
$$

denote the forecast conditional on knowing the future regimes, which can be generated recursively from 


$$
\hat{u}_{n, t+j \mid t}\left(i_{k}, i_{k-1}, \ldots, i_{1}\right)=\phi_{n, i_{j}} \hat{u}_{n, t+j-1 \mid t}\left(i_{k}, i_{k-1}, \ldots, i_{1}\right)+c_{n, i_{j}}
$$

for $c_{n j}=\alpha_{n j}+21 \beta_{n j}$. The unconditional forecast is then

$$
\begin{aligned}
& E\left(u_{n, t+k} \mid u_{n t}, s_{t}=1\right)= \\
& \sum_{i_{1}=1}^{2} \sum_{i_{2}=1}^{2} \cdots \sum_{i_{k}=1}^{2} \hat{u}_{n, t+k t}\left(i_{k}, i_{k-1}, \ldots, i_{1}\right) p_{n, 1, i_{1}} p_{n, i_{1}, i_{2}} \cdots p_{n, i_{k-1}, i_{k}} .
\end{aligned}
$$

Note the identity

$$
\begin{aligned}
f_{k t} & =r_{t+k}+\left(f_{1, t+k-1}-r_{t+k}\right)+\left(f_{2, t+k-2}-f_{1, t+k-1}\right)+\cdots+\left(f_{k, t}-f_{k-1, t+1}\right) \\
& =r_{t+k}+u_{1, t+k}+u_{2, t+k-1}+\cdots+u_{k, t+1} .
\end{aligned}
$$

Taking conditional expectations of (16),

$$
f_{k t}=E\left(r_{t+k} \mid u_{n t}, s_{t}=1\right)+\sum_{j=1}^{k} E\left(u_{j, t+j} \mid u_{n t}, s_{t}=1\right) .
$$

Thus if we supposed that the market expectation of fed funds rates for the remainder of 2009 was a constant 18 basis points,

$$
E\left(r_{t+k} \mid u_{n t}, s_{t}=1\right)=18 \quad k=1,2, \ldots, 6,
$$

Equations (17) and (15) imply a value for $f_{k t}$ that we would expect to see. These values are plotted as the dotted line in Figure 5. This prediction is uniformly above the average risk premia correction, because with a 1-year minus 6-month spread of 21 basis points, the MS predictive regressions in Table VII imply bigger risk premia when the economy is in regime 1 than observed on average.

The results of this exercise suggest that the modest upward slope of the futures curve in the summer of 2009 could easily be entirely accounted for by risk premia in these contracts, and need not be interpreted as a belief by market participants that an increase in the target fed funds rate before the end of 2009 was a material possibility.

\section{CONCLUSIONS}

In this study we have confirmed the findings of previous researchers that while it is difficult to make a better prediction of the fed funds rate than is incorporated in near-term fed funds futures contracts, for longer horizons there is a systematic gain for those taking the long position in these contracts, that is, the actual fed funds rate is likely to end up below the forward rate implied by the contract. We related this to the tendency of treasury securities of longer maturities to provide 
a higher yield on average than those of shorter maturities, and studied timevariation in the predictable contract gain over the period 1990-2006. We found that the predictable gain for these contracts is primarily coming from particular episodes of weak economic activity in the early 1990s, 1995, and 2001-2002. Although a speculator could expect a positive average gain from a long position in fed funds futures at such times, they are also associated with much more variance of the gain.

\section{BIBLIOGRAPHY}

Ang, A., \& Bekaert, G. (2002). Regime switches in interest rates. Journal of Business and Economic Statistics, 20, 163-182.

Ang, A., Bekaert, G., \& Wei, M. (2008). The term structure of real rates and expected inflation. Journal of Finance, 63, 797-849.

Bansal, R., \& Zhou, H. (2002). Term structure of interest rates with regime shifts. Journal of Finance, 57, 1997-2043.

Bekaert, G., Hodrick, R. J., \& Marshall, D. A. (1997). On biases in tests of the expectations hypothesis of the term structure of interest rates. Journal of Financial Economics, 44, 309-348.

Bundick, B. (2007). Do federal funds futures need adjustment for excess returns? A statedependent approach. Working Paper 07-08, Federal Reserve Bank of Kansas City.

Campbell, J. Y., Lo, A. W., \& MacKinlay, A. C. (1997). The Econometrics of Financial Markets. Princeton: Princeton University Press.

Campbell, J. Y., \& Shiller, R. J. (1991). Yield spreads and interest rate movements: A bird's eye view. Review of Economic Studies, 58, 495-514.

Clark, T. E., \& West, K. D. (2007). Approximately normal tests for equal predictive accuracy in nested models. Journal of Econometrics, 138, 291-311.

Cochrane, J. H., \& Piazzesi, M. (2005). Bond risk premia. American Economic Review, $95,138-160$.

Dai, Q., Singleton, K. J., \& Yang, W. (2007). Regime shifts in a dynamic term structure model of U.S. treasury bond yields. Review of Financial Studies, 20, 1669-1706.

Engel, C., \& Hamilton, J. D. (1990). Long swings in the dollar: Are they in the data and do markets know it? American Economic Review, 80, 689-713.

Evans, M. D. D. (2003). Real risk, inflation risk, and the term structure. Economic Journal, 113, 345-389.

Evans, M. D. D., \& Lewis, K. K. (1994). Do stationary risk premia explain it all? Evidence from the term structure. Journal of Monetary Economics, 33, 285-318.

Ferrero, G., \& Nobili, A. (2009). Futures contract rates as monetary policy forecasts. International Journal of Central Banking, 5, 109-145.

Garcia, R., \& Perron, P. (1996). An analysis of the real interest rate under regime shifts. Review of Economics and Statistics, 78, 111-125.

Gray, S. F. (1996). Modeling the conditional distribution of interest rates as a regimeswitching process. Journal of Financial Economics, 42, 27-62.

Gürkaynak, R. S., Sack, B., \& Swanson, E. (2007). Market-based measures of monetary policy expectations. Journal of Business and Economic Statistics, 25, 201-212. 
Hamilton, J. D. (1988). Rational-expectations econometric analysis of changes in regime: An investigation of the term structure of interest rates. Journal of Economic Dynamics and Control, 12, 385-423.

Hamilton, J. D. (1989). A new approach to the economic analysis of nonstationary time series and the business cycle. Econometrica, 57, 357-384.

Hamilton, J. D. (2008). Daily monetary policy shocks and new home sales. Journal of Monetary Economics, 55, 1171-1190.

Hamilton, J. D. (2009). Daily changes in fed funds futures prices. Journal of Money, Credit, and Banking, 41, 567-582.

Hamilton, J. D. (2010). Macroeconomics and ARCH. In T. Bollerslev, J. R. Russell, \& M. Watson (Eds.), Festschrift in Honor of Robert F. Engle (pp. 79-96). Oxford: Oxford University Press.

Inoue, T., \& Okimoto, T. (2008). Were there structural breaks in the effect of Japanese monetary policy?: Re-evaluating the policy effects of the lost decade. Journal of the Japanese and International Economies, 22, 320-342.

Kuttner, K. N. (2001). Monetary policy surprises and interest rates: Evidence from the fed funds futures market. Journal of Monetary Economics, 47, 523-544.

Krueger, J. T., \& Kuttner, K. N. (1996). The fed funds futures rate as a predictor of Federal Reserve policy. Journal of Futures Markets, 16, 865-879.

Longstaff, F. A. (2000). The term structure of very short-term rates: New evidence for the expectations hypothesis. Journal of Financial Economics, 58, 397-415.

Piazzesi, M., \& Swanson, E. (2004). Futures prices as risk-adjusted forecasts of monetary policy. Working Paper 10547, National Bureau of Economic Research.

Piazzesi, M., \& Swanson, E. (2008). Futures prices as risk-adjusted forecasts of monetary policy. Journal of Monetary Economics, 55, 677-691.

Rudebusch, G. D. (1995). Federal reserve interest rate targeting, rational expectations, and the term structure. Journal of Monetary Economics, 35, 245-274.

Rudebusch, G. D. (1998). Do measures of monetary policy in a VAR make sense? International Economic Review, 39, 907-931.

Sack, B. (2004). Extracting the expected path of monetary policy from futures rates. Journal of Futures Markets, 24, 733-754.

Sims, C., \& Zha, T. (2006). Were there regime switches in U.S. monetary policy? American Economic Review, 96, 54-81.

Smith, A., Naik, P. A., \& Tsai, C.-L. (2006). Markov-switching model selection using Kullback-Leibler divergence. Journal of Econometrics, 134, 553-577.

West, K. D. (2006). Forecast evaluation. In G. Elliott, C. W. J. Granger, \& A. Timmermann (Eds.), Handbook of Economic Forecasting, Vol. 1 (pp. 100-134). Amsterdam: Elsevier. 